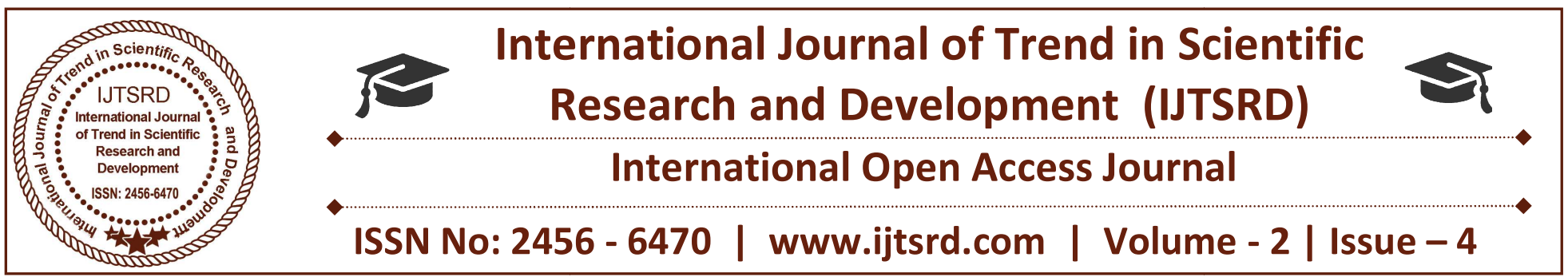

\title{
Transactional Analysis and Counseling: Insightful Thoughts
}

\author{
Dr. Nimmi Maria Oommen \\ Assistant Professor of Education, Titus II Teachers College, Tiruvalla, Kerala, India
}

\section{ABSTRACT}

Transactional analysis (TA) is a widely recognized form of modern psychology that involves a set of practical conceptual tools designed to promote personal growth and change. It is considered a fundamental therapy for well-being and for helping individuals to reach their full potential in all aspects of life. Transactional analysis is a social psychology developed by Eric Berne, MD (d.1970). Berne's theory consists of certain key concepts that practitioners use to help clients, students, and systems analyze and change patterns of interaction that interfere with achieving life aspirations. This is an article which gives insights on Transactional analysis and counselling.

Keywords: Transactional analysis, counseling, therapist

\section{INTRODUCTION}

Transactional Analysis refers to the psychoanalytic process wherein the interpersonal behaviors are studied. It is a social psychological model that talks about the personal growth and personal change, i.e., identifying the ego states of each individual to understand their behaviors and altering them to solve the emotional problems.

\section{KEY FEATURES OF TA}

$>$ All people are important and their concerns are valid.

$>$ All people should be treated as equals and with respect.

$>$ With a few exceptions, all people have the ability to think as adults.

$>$ All people decide their own destiny and can make changes to it.

\section{TRANSACTIONAL ANALYSIS: VIDE CONTEXTS \\ Areas- \\ counseling, education, organizational development, and psychotherapy.}

The counseling specialization - by professionals working in such diverse contexts as social welfare, health care, pastoral work, prevention, mediation, process facilitation, multicultural work, and humanitarian activities, to name a few.

Educational transactional analysis - used by practitioners working in training centers, preschools, elementary and high schools, universities, and institutions that prepare teachers and trainers as well as in support of learners of all ages to thrive within their families, organizations, and communities.

\section{Organizational transactional analysis -} organizations using transactional analysis concepts and techniques to evaluate an organization's developmental processes and challenges as well as its dysfunctional behaviors.

Psychotherapists -utilize transactional analysis to facilitate their clients' capacities for self-actualization and healing by learning to recognize and change old, self-limiting patterns.
TRANSACTIONAL
ANALYSIS
AND

\section{COUNSELLING}
In counselling TA therapy is very versatile, for it can be used in a wide range of areas and incorporates key themes from humanistic, integrative, psychoanalytical, psychodynamic therapies. Though it is commonly recognised as a brief and solution- focused approach, transactional analysis can also be applied as an effective long-term, in-depth therapy . 
TA therapy is based on the theory that each person has three ego states: parent, adult and child. These are used along with other key transactional analysis concepts, tools and models to analyze how individuals communicate and identify what interaction is needed for a better outcome. Throughout therapy, the TA therapist will work directly on here and now problem solving behaviours, whilst helping clients to develop day-to-day tools for finding constructive creative solutions. The ultimate goal is to ensure clients regain absolute autonomy over their lives. Eric Berne defines this autonomy as the recovery of three vital human capacities - spontaneity, awareness and intimacy.

Transactional analysis is a talking therapy and sessions are designed to explore an individual's personality and how this has been shaped by experience - particularly those stemming from childhood. This is achieved through skillful questioning and the utilisation of various models, techniques and tools. Sessions can be carried out in the form of one-on-one counselling, or with families, couples or groups.

$>$ The atmosphere that supports transactional analysis is non-judgemental, secure and respectful, ensuring that a positive relationship is forged between the therapist and client(s) in order to provide a model for subsequent relationships and communication that are developed outside of therapy.

$>$ In this setting the therapist works collaboratively with the individual to identify what has gone wrong in their communication and provide opportunities for them to change repetitive patterns that limit their potential.

$>$ TA therapists recognise that we all have the potential to live the life we want, rather than the life we are programmed to live. Sometimes however this potential is hindered by repetitive patterns or 'unconscious scripts' that stem from childhood decisions and teachings.

\section{KEY CONCEPTS OF TRANSACTIONAL ANALYSIS}

The personality for Transactional Analysis, for Berne, is based on the recognition of three quite different ego states, called specifically the Parent, Adult and Child.

\section{EGO-STATES}

Ego-states refer to the three major parts of an individual's personality, and they each reflect an entire system of thought, feeling and behaviour. These determine how individuals express themselves, interact with each other and form relationships.

\section{These are:}

$>$ Parent ego-state - A set of thoughts, feelings and behaviours learnt from our parents and other important people. This part of our personality can be supportive or critical.

$>$ Adult ego-state - Relates to direct responses in the 'here and now' that are not influenced by our past. This tends to be the most rational part of our personality.

$>$ Child ego-state - A set of thoughts, feelings and behaviours learnt from our childhood. These can be free and natural or strongly adapted to parental influences.

\section{UNCONSCIOUS SCRIPTS}

TA therapists use script theory to identify unconscious scripts. These will be analysed using the ego-state model, and their identification is crucial to helping clients realise how certain permissions and prohibitions they received as a child are impacting their lives and how they communicate. These unconscious scripts often exist as repetitive patterns of behaviour, thoughts and feelings - characteristics that suggest the child ego-state is overbearing and tainting other parts of a person's personality.

\section{TRANSACTIONS}

When individuals communicate, their ego-states interact to create transactions. If the ego-states interact and blend in a healthy way, transactions tend to be healthier, but sometimes ego-states can contaminate each other to create a distorted view of the world. Transactions may be classified as straightforward, crossed-up, or ulterior, and understanding these is key to conflict resolution.

\section{STROKES}

Strokes refer to compliments, acceptance and recognition, which are influential in how people lead their lives. TA therapy recognises that we are greatly motivated by the reinforcement we get as children, and if this was dysfunctional, we are likely to adopt dysfunctional patterns of living as we get older.

\section{INTIMACY}

Another motivation recognised in transactional analysis is intimacy. Similarly to strokes, if the intimacy a child experiences is dysfunctional, then they will learn that this type of intimacy is the best he 
or she can do to meet basic needs and communicate with others. This can lead to the development of repetitive patterns of behaviour that can hinder a person's potential.

\section{RE-DECISION}

This refers to an individual's capacity to re-decide and make changes to certain decisions made as a child that stem from unconscious scripts. Re-decision reflects the assumption of TA therapy that individuals have the potential to lead their lives as they choose. This power is released after a re-decision is made while a client is in their child-ego state.

Ultimately, therapists will use these concepts in transactional analysis therapy to promote structural rearrangement of a client's child ego-state. They will encourage clients to challenge their current beliefs and the way he or she uses their life script. This will help them to better understand the direction and patterns of their life for themselves, and this awareness can help them to make the decision to change their behaviour.

\section{BENEFICIARY...}

$>$ Designed to promote personal growth and change, transactional analysis offers the opportunity to develop all kinds of easy to learn skills that can be applied to all areas of life. This makes the therapy valuable for helping to solve many types of problems, and it has been successfully applied in wide variety of settings outside of counselling, including organizational training and consultancy, parenting, education and coaching.

$>$ Essentially transactional analysis can be used in any field where there is a need for understanding of individuals, communication and relationships. As a result, it is particularly useful where there are issues of conflict, confusion or where something is lacking. Relationship issues - between families, friends and couples - tend to benefit greatly, as TA encourages clients to address problems that have built up over time.

\section{ROLE OF COUNSELOR}

The counselor and the client both work together to establish the specific goals of therapy in a fruitful manner. In other words, the counselor will use his knowledge to address a concern introduced by the client rather than telling the client what issues he needs to focus on.

\section{CONCLUSION}

Many people find TA therapy appealing as promotes an equal relationship between client and therapist, in which the client is encouraged to focus on their commitment to change. Berne believed everyone has the capacity to decide what they want for their lives, and the therapy helps clients to recognise their worth and value in order to go about achieving these goals.

\section{REFERENCES}

1. Crow, L.D. and Crow A.(1966). Introduction to Guidance. New York: Mc Graw Hills.

2. Crowell, B.M.E.(1963).Guidance and Counselling in Group. New York: Mc Graw Hills.

3. Currie, J.(1981). The Barefoot Counsellor. Bangalore: Asian Trading Company.

4. Nayak A. K, Guidance and counselling, APH Publishing Corporation, New Delhi, 2004.

5. Srivasthava K. K, Principles of guidance and counselling, kanishka, New Delhi, 2003.

6. https://www.itaaworld.org/what-transactionalanalysis

7. https://www.counsellingdirectory.org.uk/transactional-analysis.html 